\title{
Reconstruction of isolated scaphoid dislocation with carpal dissociation, associated with a carpal anomaly
}

\author{
Matthijs P. Somford • Maarten F. A. M. Sturm • \\ Jos P. A. M. Vroemen
}

Received: 3 December 2009/Accepted: 30 June 2010/Published online: 31 July 2010

(c) The Author(s) 2010. This article is published with open access at Springerlink.com

\begin{abstract}
A case is presented of isolated scaphoid dislocation with carpal dissociation in the presence of a lunato-triquetral coalition. We present the treatment and follow-up of this case. In addition, the literature on scaphoid dislocation and its treatment is reviewed. We emphasize the need to reconstruct the carpal alignment and scapho-lunate linkage.
\end{abstract}

Keywords Scaphoid dislocation · Axial carpal dissociation $\cdot$ Lunato-triquetral coalition $\cdot$ Carpal trauma

Present Address:

M. P. Somford ( $\square)$

Department of Orthopaedic Surgery, AMC Hospital,

Meibergdreef 9, 1105 AZ Amsterdam, The Netherlands

e-mail: mp_somford@hotmail.com

M. P. Somford

Department of General Surgery, Amphia Hospital,

Breda, The Netherlands

M. F. A. M. Sturm

Department of Radiology, Amphia Hospital,

Breda, The Netherlands

e-mail: MSturm@amphia.nl

J. P. A. M. Vroemen

Department of General Surgery, Amphia Hospital,

Molengracht 21, 4818 CK Breda,

The Netherlands

e-mail: JVroemen@amphia.nl

J. P. A. M. Vroemen

Traumatology Department, Amphia Hospital,

Breda, The Netherlands

\section{Case report}

A 47-year-old male patient was admitted to our emergency department after a head-on collision with another scooter. He sustained a trauma to the wrist without any additional injuries. His medical history showed a conservatively treated fracture of the left distal ulna 34 years earlier, which was asymptomatic at the time of injury.

He complained of severe pain at his left wrist. On physical examination, there was an obvious hematoma at the volar side of the left wrist (Oestern and Tscherne classification of closed fractures grade II [1]). The function of the thumb and index finger was unimpaired, but he was unable to move the wrist and other fingers because of pain. There were no signs of neurovascular damage.

Conventional radiological examination showed the classic appearance of a scaphoid dislocation, with its attachment remaining to the trapezium, and discongruency of the other carpals. An apparent abnormality of the lunate and triquetrum was present but initially not quite understood (Fig. 1). There was a disruption between the capitate and the hamate, while the capitate was wedged between the scaphoid and the lunate. The third metacarpal remained attached to the capitate. This lesion is known as an axial carpal dissociation (Fig. 2).

A computed tomography (CT) scan revealed, apart from the above-mentioned diagnosis, the exact nature of the abnormality of the proximal row of the carpal bones; this patient appeared to have a coalition of the lunate and triquetrum. This anomaly is known as the os lunatotriquetrum. The base of the third metacarpal was luxated volarly.

Comparison X-rays of the right wrist also showed a lunato-triquetral coalition, but of a different type (Fig. 3). 


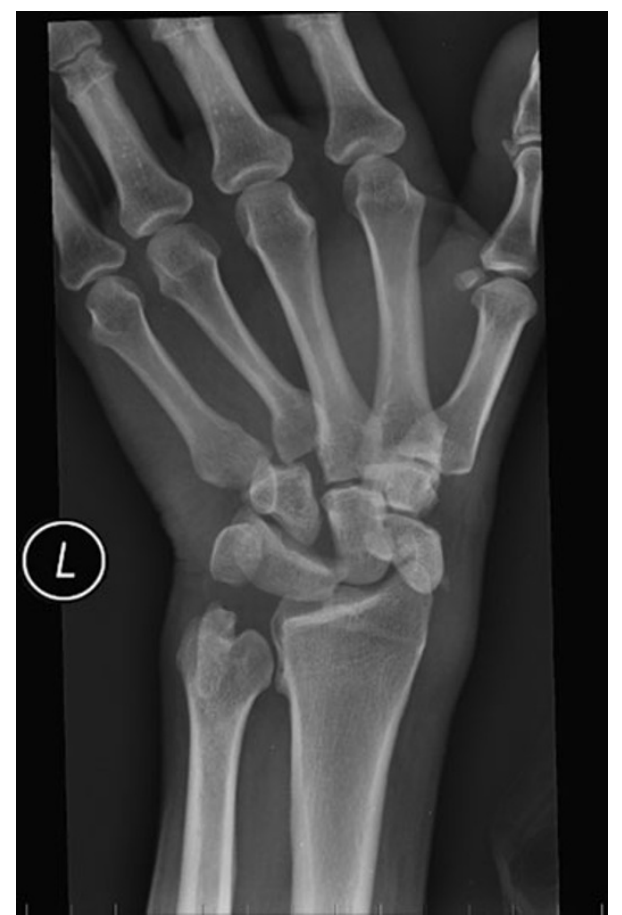

Fig. 1 An isolated scaphoid dislocation with carpal dissociation with a carpal anomaly. The sequella of a conservatively treated ulnar fracture 34 years earlier is still visible

The patient was brought to the operating room for open reduction and internal fixation of this complex wrist trauma. Because of the evident hematoma and the palpable dislocated osseous structures on the volar side, a volar approach was chosen. After the skin incision and evacuation of the hematoma, the volar ligamentous structures were found to be ruptured. A carpal tunnel release was performed for better exposure and decompression of the median nerve. Without any further elaborate preparation, the osseous structures could easily be identified. The dissociation between the hamate and capitate was apparent. The scaphoid was stuck behind the styloid process of the radius. The bases of the second and third metacarpal bone were displaced proximally and volarly, along with the capitate.

The reconstruction started with the reduction of the osseous structures, which was relatively simple. However, the instability was of such a degree that it was hard to maintain. In order to maintain preliminary reduction and length, a joint-bridging external fixation was applied from the radial shaft to the second metacarpal. The radioscaphocapitate and radioscapholunate ligament were torn, while the radiolunate ligaments were still intact. The torn ligaments were sutured and augmented with the use of Mitek ${ }^{\circledR}$ bone anchors: one anchor in the lunate and one in the scaphoid. The torn capitatehamate ligament was treated in the same manner, with one anchor in the capitate and one in the hamate. After re-establishing the carpal alignment, a 16-mm threaded K-wire (Fracture Fixation System $^{\circledR}$, FFS, Orthofix) was drilled from the scaphoid to the lunate to enforce the repair. The remaining volar dislocation of the second and third metacarpal, resulting in tilting of the capitate, was corrected by reduction under direct vision and fixed with another $16-\mathrm{mm} \mathrm{FFS}^{\circledR}$ wire through the base of the second and third metacarpal into the base of the fourth (Fig. 4).

Post-operatively, the external fixator was kept in position for 6 weeks as a neutralization device (Fig. 5). The patient was encouraged to exercise his fingers and was allowed full pro- and supination. In this period, no complications occurred. After the external fixation was removed, the patient started to mobilize his wrist under physiotherapeutic guidance. Radiological follow-up showed a good anatomical reduction after 6 and 10 weeks. After 10 weeks, the FFS ${ }^{\circledR}$ wires were removed and full-functional rehabilitation was continued.
Fig. 2 Reconstruction of the traumatic situation on a sawbone, showing clearly the amount of displacement and involved carpal bones
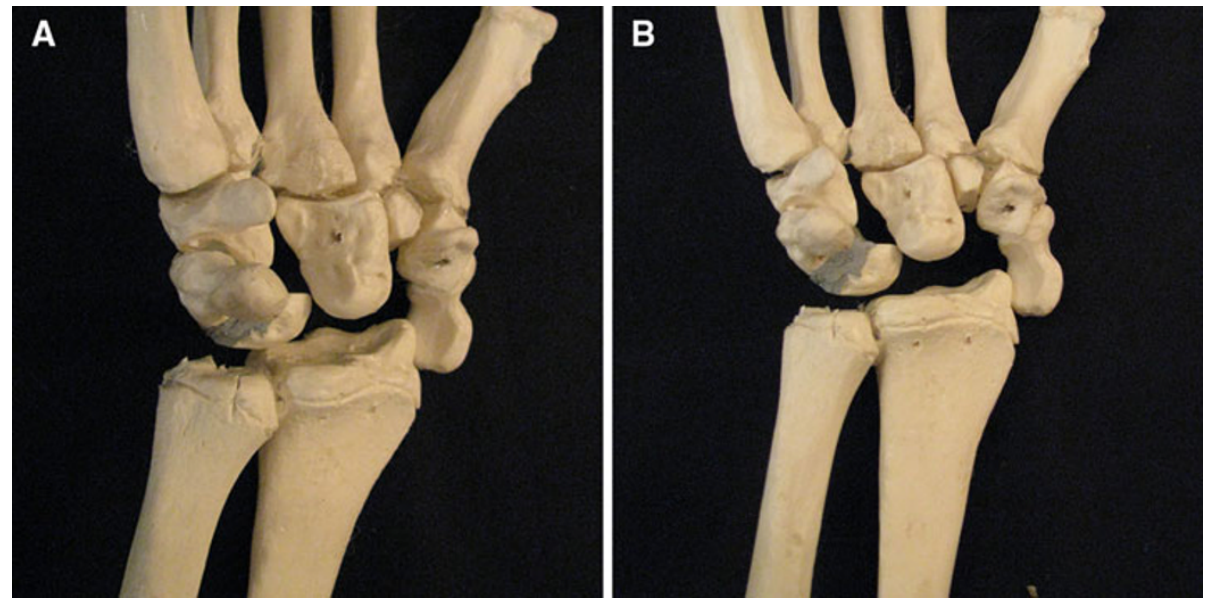


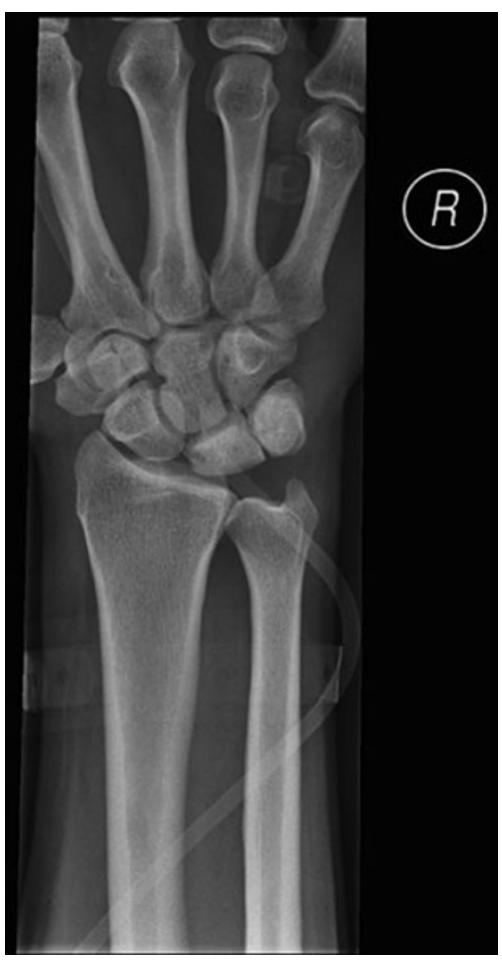

Fig. 3 Comparison X-ray of the right wrist showing a fibro-cartilaginous coalition of the lunate and triquetrum

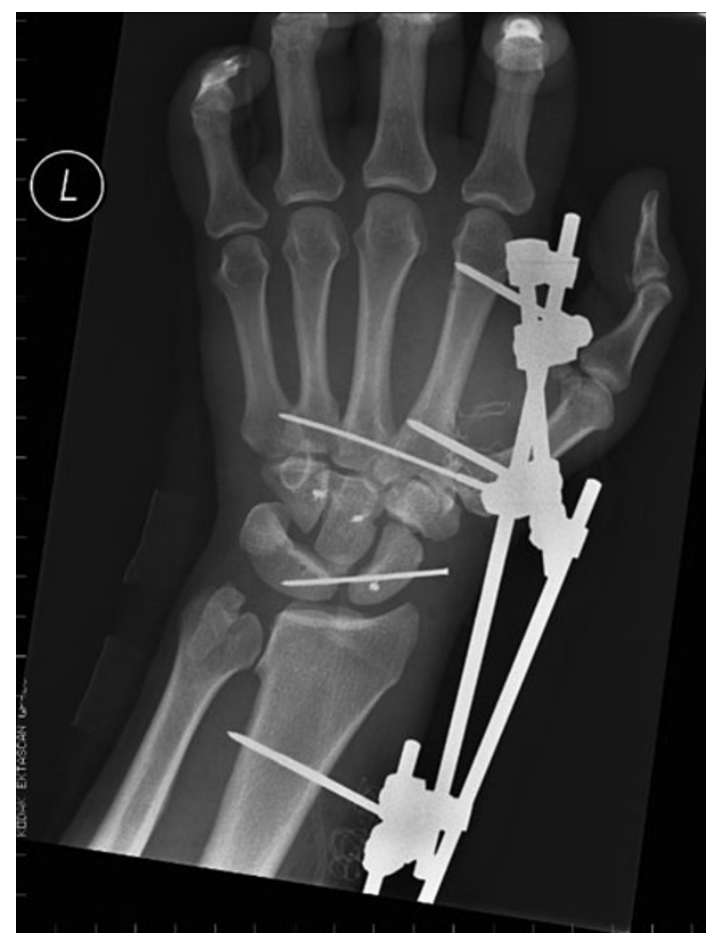

Fig. 5 The situation immediately after operative repair
Fig. 4 Operative steps (a-d) as described in the text. a Initial situation. b After stabilization with an external fixator.

c Scapho-lunate dissociation corrected with Mitek ${ }^{\circledR}$ bone anchors. d Final situation after placement of the FFS ${ }^{\circledR}$ wires, realigning the bases of the metacarpals and establishing carpal alignment

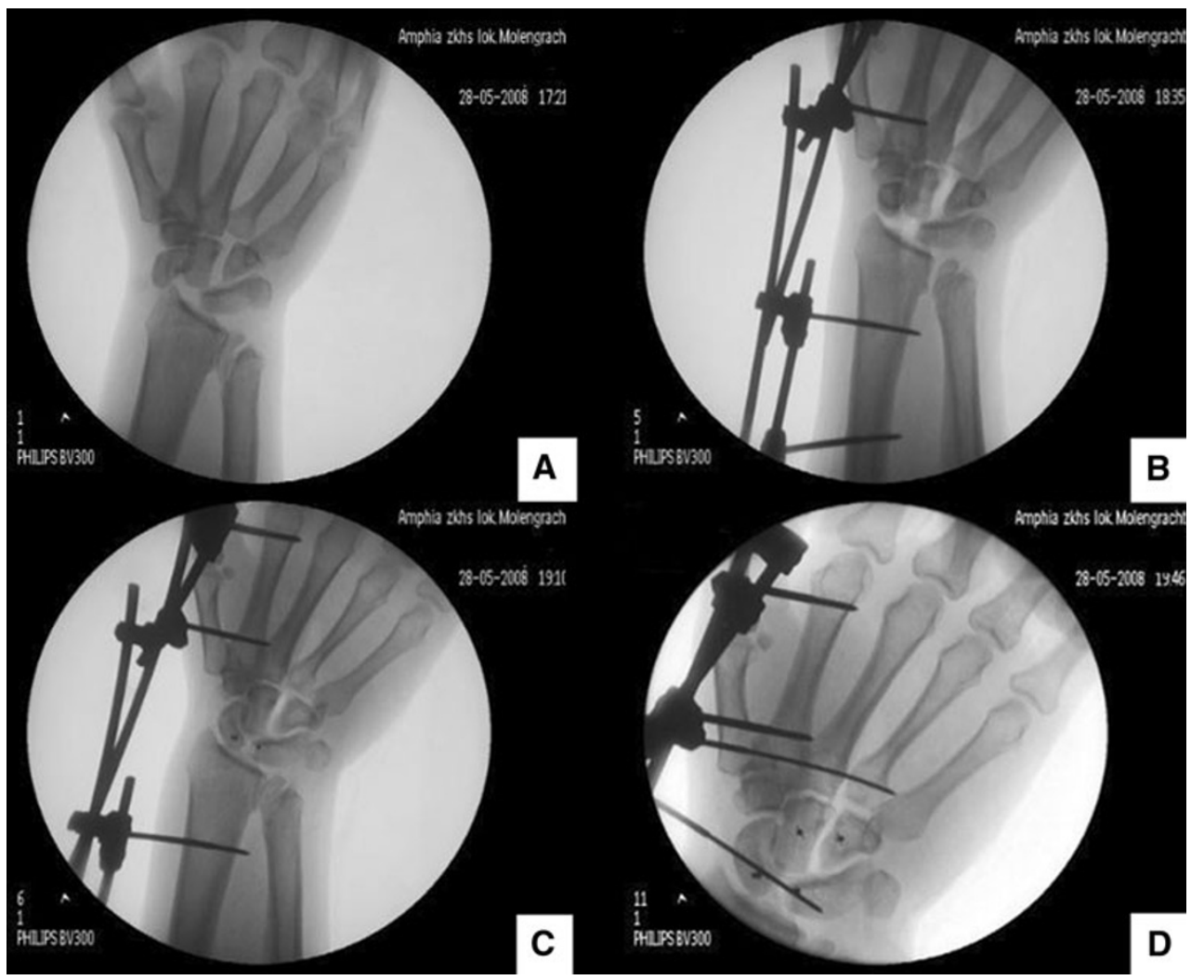


Table 1 Objective wrist function after 9 months

\begin{tabular}{lllll}
\hline & Pro-supination & $\begin{array}{l}\text { Dorsal/palmar } \\
\text { flexion }\end{array}$ & $\begin{array}{l}\text { Radial/ulnar } \\
\text { adduction }\end{array}$ & $\begin{array}{l}\text { Strength (JAMAR } \\
\text { dynamometer) (kg) }\end{array}$ \\
\hline Left hand & $90-0-70$ & $50-0-50$ & $20-0-40$ & 25.0 \\
Right hand & $90-0-90$ & $80-0-50$ & $30-0-40$ & 55.3 \\
\hline
\end{tabular}

After 3 months, the patient reported satisfactory wrist function. He did not complain of pain during rest. Strenuous efforts of the wrist were tolerated with moderate pain.

After 9 months, an objective evaluation was performed. Despite the satisfactory function in daily activities, the measured function of the left wrist was impaired compared to the right (Table 1). The Disabilities of the Arm, Shoulder and Hand (DASH) score was 30.8 out of 100 . The Patient-Specific Functional and Pain Scale (PSFS) score [2] was 17 out of 100 and the Patient-Rated Wrist/Hand Evaluation (PRWHE) [3] was 39 out of 100. The Visual Analogue Pain Scale (VAS) score was 0 at rest.

A clenched fist X-rays showed discrete residual scapholunate gap (Fig. 6).

\section{Discussion}

Although the axial dissociation was evident from the beginning, the aberrant aspect of the carpus was not fully understood after conventional X-rays. The anomaly of the lunate and triquetrum became apparent after CT scanning. The coalition of the lunate and triquetrum is the most common anomaly of the carpus and is often bilateral [4]. The incidence varies from $0.1 \%$ in the general population of European descent up to $9.5 \%$ in female black Africans
$[5,6]$. There are four types of coalition, as classified by Devilliers Minnaar [7] in 1952:

Type 1: incomplete fusion resembling a pseudo-arthrosis (fibro-cartilage coalition)

Type 2: incomplete osseous fusion

Type 3: complete osseous fusion (os lunato-triquetrum) Type 4: complete osseous fusion associated with other carpal anomalies

In our case, the left hand had a type 3 coalition and the right a type 1 . Both wrists were symptomless before the trauma. The anomaly had no consequences for the eventual treatment.

An isolated scaphoid dislocation is a rare condition. An isolated scaphoid dislocation combined with an axial carpal dissociation is extremely rare: only a few cases are known in the English literature, starting with Buzby's in 1934 [8-13].

The proposed injury mechanism is that there is an axial trauma of the wrist while the hand is gripping an object in slight ulnar deviation [13]. Thus, as a result of the trauma, the hand is deviated ulnarly with force, as in a motorcyclist holding his handle bar and hitting an object. The force needed to obtain an axial carpal injury is considerable and often results in a fracture of the scaphoid or styloid process of the radius. For the same reason, these injuries mostly
Fig. 6 Clenched fist radiograph compared with the relaxed condition

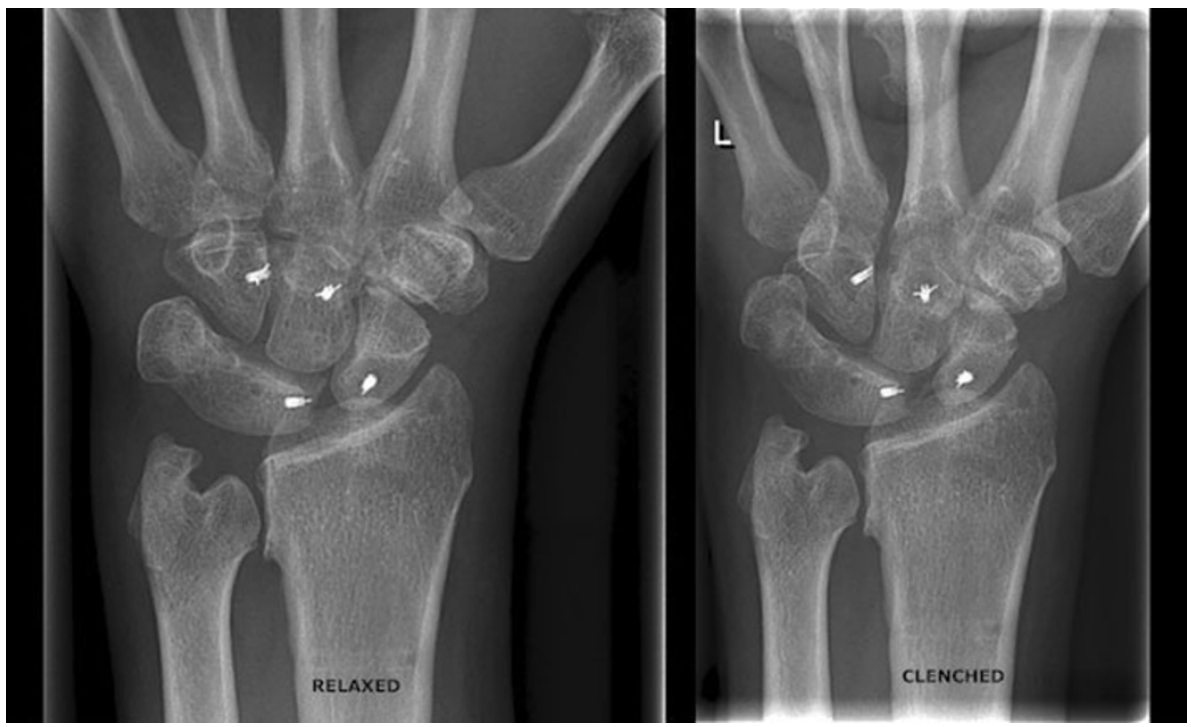




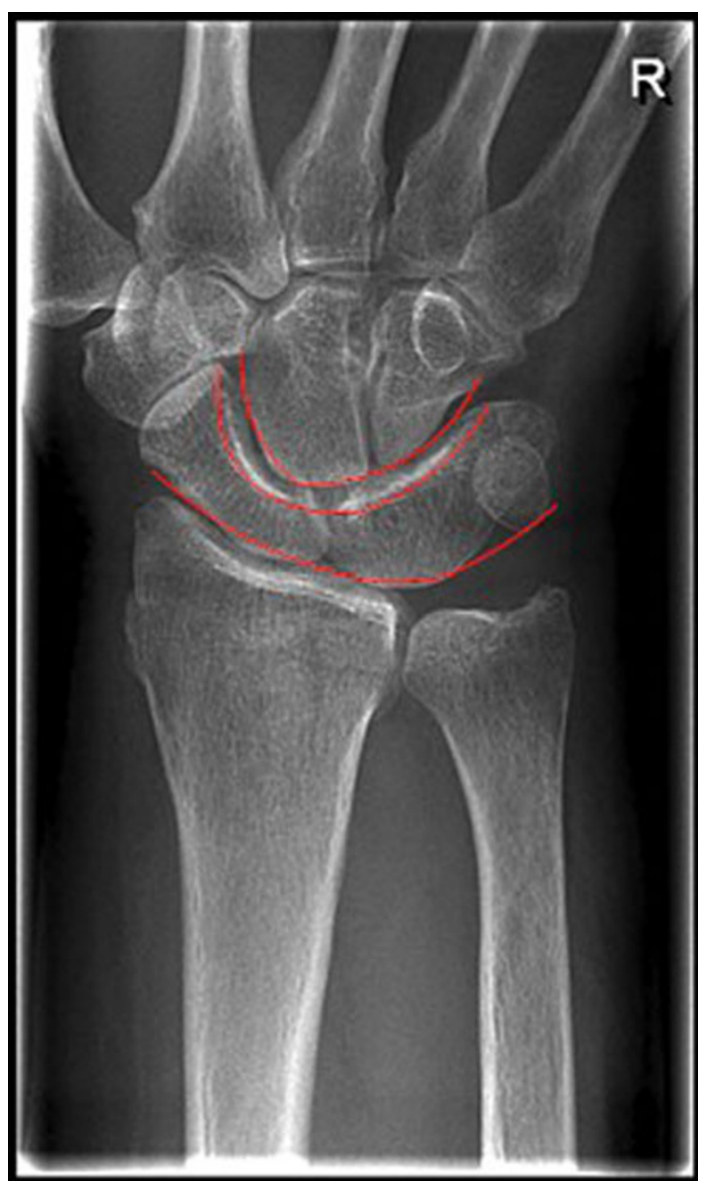

Fig. 7 The arcs of Gilula drawn on another patient's X-ray with an os lunato-triquetrum. The first arc is along the proximal border of the proximal carpal row, the second along the distal border of the proximal carpal row, and the third along the border of the distal carpal row

involve massive soft tissue trauma to the hand and present often as open fractures $[11,14]$.

On plain radiographic examination, the correct interpretation of carpal injury is greatly facilitated by identifying the arcs of Gilula (Fig. 7) [15]. These arcs are three radiographic lines. If any of these arcs is disrupted, ligamentous carpal injury should be suspected. Arthrograms or magnetic resonance imaging (MRI) can be used to assess ligamentous injury in case of unobvious (sub)luxation [10]. CT scanning is useful in pre-operative planning.

The most common classification of axial carpal dislocations is by Garcia-Elias et al. [14]. They divided the dislocation into an axial-radial, axial-ulnar, or combined axialradial-ulnar pattern. Scaphoid dislocations are not included in this classification. A specific classification for scaphoid dislocation is presented by Richards et al. [11]. The injury pattern can be classified as simple (isolated scaphoid dislocation with an intact distal carpal row) or complex (scaphoid dislocation with axial carpal dislocation). A refinement of this classification was made by Leung et al. [16]. This resulted in the classification of scaphoid dislocation into:

- Primary versus secondary: primary dislocations result directly from the injury, whereas secondary dislocations are a persisting dislocation of the scaphoid, even after closed reduction of the proximal carpus, mostly because of ligament interposition

- Simple versus complex: dislocations involving only the radioscaphoid and scapholunate articulations are classified as simple, whereas complex dislocations involve hamate, capitate, and intermetacarpal joint surfaces

- Partial versus complete dislocation: in case of persisting (distal) soft tissue attachments to the scaphoid, there is a partial dislocation; if all attachments are lost, a complete dislocation is present

According to Leung et al., our patient had a primary complex partial dislocation.

Treatment options in the current literature of simple or complex scaphoid dislocation vary from closed reduction to open reposition and ligamentous repair. Because of scapholunate dissociation, we advocate fixation and ligamentous repair after reduction to prevent late carpal collapse. To our knowledge, the fixation with Mitek ${ }^{\circledR}$ bone anchors in this specific injury has not been reported previously in the literature. It offers non-space-consuming, dynamic, and permanent fixation.

In the scarce current literature, a slight loss of wrist motion after this injury is reported after operative treatment, but the subjects returned to normal daily activities. The low incidence of avascular necrosis of the scaphoid in partial scaphoid dislocation is probably due to the remaining (distal) scaphotrapezial ligaments, providing sufficient blood supply [17].

Open Access This article is distributed under the terms of the Creative Commons Attribution Noncommercial License which permits any noncommercial use, distribution, and reproduction in any medium, provided the original author(s) and source are credited.

\section{References}

1. Tscherne H, Oestern HJ (1982) A new classification of soft-tissue damage in open and closed fractures (author's transl). Unfallheilkunde 85(3):111-115

2. Stratford P, Gill C, Westaway M, Binkley J (1995) Assessing disability and change on individual patients: a report of a patient specific measure. Physiother Can 47:258-263

3. MacDermid JC (1996) Development of a scale for patient rating of wrist pain and disability. J Hand Ther 9(2):178-183

4. van Schoonhoven J, Prommersberger KJ, Schmitt R (2001) Traumatic disruption of a fibrocartilage lunate-triquetral coalition-a case report and review of the literature. Hand Surg 6(1):103-108 
5. Garn SM, Frisancho AR, Poznanski AK, Schweitzer J, McCann MB (1971) Analysis of triquetral-lunate fusion. Am J Phys Anthropol 34(3):431-433

6. Cockshott WP (1963) Carpal fusions. Am J Roentgenol Radium Ther Nucl Med 89:1260-1271

7. Devilliers Minnaar AB (1952) Congenital fusion of the lunate and triquetral bones in the South African Bantu. J Bone Joint Surg Br 34-B(1):45-48

8. Sides D, Laorr A, Greenspan A (1995) Carpal scaphoid: radiographic pattern of dislocation. Radiology 195(1):215-216

9. Connell MC, Dyson RP (1955) Dislocation of the carpal scaphoid; report of a case. J Bone Joint Surg Br 37-B(2):252-253

10. Horton T, Shin AY, Cooney WP 3rd (2004) Isolated scaphoid dislocation associated with axial carpal dissociation: an unusual injury report. J Hand Surg Am 29(6):1102-1108

11. Richards RS, Bennett JD, Roth JH (1993) Scaphoid dislocation with radial-axial carpal disruption. AJR Am J Roentgenol 160(5):1075-1076
12. Buzby BF (1934) Isolated radial dislocation of carpal scaphoid. Ann Surg 100:553-555

13. Taylor AR (1969) Dislocation of the scaphoid. Postgrad Med J 45(521):186-189

14. Garcia-Elias M, Dobyns JH, Cooney WP 3rd, Linscheid RL (1989) Traumatic axial dislocations of the carpus. J Hand Surg Am 14(3):446-457

15. Gilula LA (1979) Carpal injuries: analytic approach and case exercises. AJR Am J Roentgenol 133(3):503-517

16. Leung YF, Wai YL, Kam WL, Ip PS (1998) Solitary dislocation of the scaphoid. From case report to literature review. J Hand Surg Br 23(1):88-92

17. Milankov M, Somer T, Jovanović A, Brankov M (1994) Isolated dislocation of the carpal scaphoid: two case reports. J Trauma 36(5):752-754 